\title{
Comunicação sobre as tribos vencidas ${ }^{1}$ Communication on the conquered tribes
}

\author{
Cristiano Rodriguez Batista \\ Universidade Estadual de Campinas, Campinas, Brasil \\ cristianorodriguez@gmail.com
}

Resumo: É comum em várias cidades do país se deparar com nomes indígenas ou de escritores designando ruas, bairros ou até mesmo cidades. Este artigo pretende analisar o processo de homenagem e, consequente, redução do sentido pela qual passam etnias indígenas e a literatura. A partir da ideia benjaminiana de que todo monumento cultural é também um monumento da barbárie, pretende-se mostrar como tais homenagens guardam, também, marcas de barbárie e simplificação.

Palavras-chave: tribos vencidas; Walter Benjamin; monumentalização da barbárie; Linha Verde Literária.

Abstract: It is common in cities across the country, we can see indigenous names or writers designating streets, neighborhoods or even cities. This article analyzes the honor process and, consequently, reduced sense in which indigenous groups and literature pass by. From Benjamin's idea that all cultural monument is also a monument of barbarism, we intend to show how such honors guard, too, barbarism and simplification brands.

Keywords: conquered tribes; Walter Benjamin; monumentalization of barbarism; Linha Verde Literária.

\section{Introdução}

É certo que a civilização brasileira não está ligada ao elemento indiano [i.e. indígena], nem dele recebeu influxo algum; e isto basta para não ir buscar entre as tribos vencidas os títulos da nossa personalidade literária. Mas se isto é verdade, não é menos certo que tudo é matéria de poesia, uma vez que traga as condições do belo ou os elementos de que ele se compõe. Os que, como o Sr. Varnhagen, negam tudo aos primeiros povos deste país, esses podem logicamente excluí-los da poesia contemporânea. Parece-me, entretanto, que, depois das memórias que a este respeito escreveram os Srs. Magalhães e Gonçalves Dias, não é lícito arredar o elemento indiano da nossa aplicação intelectual. Erro seria constitui-lo um exclusivo

\footnotetext{
${ }^{1}$ Este artigo foi elaborado ao longo da disciplina "A vingança das 'tribos vencidas': antropologia e literatura a partir de Eduardo Viveiros de Castro", na UNICAMP, no primeiro semestre de 2015, ministrada pelo Prof. Dr. Eduardo Sterzi.
} 


\begin{abstract}
patrimônio da literatura brasileira; erro igual fora certamente a sua absoluta exclusão. As tribos indígenas, cujos usos e costumes João Francisco Lisboa cotejava com o livro de Tácito e os achava tão semelhantes aos dos antigos germanos, desapareceram, é certo, da região que por tanto tempo fora sua; mas a raça dominadora que as frequentou colheu informações preciosas $\mathrm{e}$ no-las transmitiu como verdadeiros elementos poéticos. A piedade, a minguarem outros argumentos de maior valia, devera ao menos inclinar a imaginação dos poetas para os povos que primeiro beberam os ares destas regiões, consorciando na literatura os que a fatalidade da história divorciou (ASSIS, 1959, p. 29).
\end{abstract}

No texto intitulado Instinto de nacionalidade, Machado de Assis se refere aos índios, que apareciam na literatura brasileira do período romântico, como "tribos vencidas". Ele se pergunta sobre a influência do elemento indígena no instinto de nação, o qual a literatura brasileira daquele período se empenhava em construir. A conclusão é de que não há possibilidade desse elemento figurar como grande marca patrimonial para a nossa literatura, mas aponta o elemento indígena como um legado, ao mesmo tempo brasileiro e universal. Tal legado deveria aparecer se: fonte de aporte para o belo; ou por piedade, numa espécie de união, matrimônio "na literatura os que a fatalidade da história divorciou". Teria se realizado esse matrimônio? Há alguma aproximação possível entre os poetas e os índios? Essas perguntas, se não respondidas, serão problematizadas no decorrer desse texto.

\title{
2 Comoditização de elementos culturais
}

O sociólogo André Vereta Nahoum, em sua tese intitulada Selling cultures: the traffic of cultural representations from the Yawanawa, diz que cresceu nos últimos anos o interesse por produtos e serviços no intuito de transmitir conhecimento de tribos indígenas. Toda a tradição transmitida de geração a geração entre os indígenas possui uma miríade de conhecimentos acerca do ambiente no qual vivem, um domínio de todos os sinais que fauna e flora são capazes de emitir que possibilitam uma leitura que a ciência está muito longe de alcançar. Ainda segundo Nahoum, populações urbanas e indústrias passaram a ter maior interesse por parte desse conhecimento comum aos indígenas de algumas regiões: principalmente, práticas cotidianas, rituais, dieta alimentar, medicina alternativa e técnicas especiais de trabalho com a natureza.

Vale lembrar que os índios focalizados no estudo citado são os mesmos que inspiraram uma coleção da Cavalera, da marca Animale, e chegaram a participar do São Paulo Fashion Week 2015.

Em alguns casos, os índios, detentores de uma consciência de si em relação ao espaço ocupado perante a sociedade capitalista, tornaram-se agentes no processo de comoditização de elementos culturais em benefício do seu próprio grupo, aumentando suas forças e incorporando o resultado desse comércio em prol da sua organização social. Como podemos supor, há situações nas quais o oposto acontece, o índio ocupa o local daquele que perde na negociação com o mercado. 
Ao ser perguntado sobre o momento atual da "antropologia urbana", Eduardo Viveiros de Castro diz um pouco sobre seu interesse pelo pensamento indígena:

\begin{abstract}
Vocês estão falando, suponho, da chamada "antropologia das sociedades complexas", das chamadas sociedades nacionais de tradição cultural europeia (ou euroasiática). Boa parte do que a antropologia fez ao se aplicar às sociedades de tradição cultural ocidental e de organização política estatal centralizada limitava-se a projetar os conceitos e o tipo mesmo de objeto característico da antropologia clássica para o contexto urbano. O que o xamã está fazendo é um pouco isso: esculpindo sujeitos nas pedras, esculpindo conceitualmente uma forma humana, isto é, subtraindo da pedra tudo aquilo que não deixava ver a "forma" humana ali contida. Os filósofos costumam usar a palavra "antropomorfismo" como censura. Eu, ao contrário, acho o antropomorfismo um gesto intelectual fascinante. [...] O equivalente funcional do xamanismo indígena á a ciência. É o cientista, é o laboratório de física de altas energias, é o acelerador de partículas. O chocalho do xamã é um acelerador de partículas (SZTUTMAN, 2007, p. 43-45).
\end{abstract}

Para Viveiros de castro, a cultura indígena possui uma complexidade intrínseca, além de seguir construindo sentido acerca de si, como qualquer sociedade que sobrevive. Ainda nas palavras de Viveiros de Castro, "Um povo indígena é uma multiplicidade viva, em perpétuo devir, em perpétua divisão, recombinação, diferenciação" (CASTRO, 2011a, p. 261). Ou seja, é rechaçada a ideia de sociedade atrasada propagada durante anos, a cultura indígena construiu e segue construindo sentido acerca de si e das categorias de pensamento que lhe são próprias.

No entanto, à medida que o índio ocupa o lugar de fonte de imagens de uma grife, possuidores de um ritual de cura, entre outras mercadorias culturais, de danças típicas, observamos uma cristalização e consequente redução no sentido que eles podem conferir à humanidade. No lugar de tentativas de que com a epistemologia europeia consigamos construir algum sentido sobre o que é a cultura indígena, o homem indígena, o mercado reifica o elemento "índio" em um bem cultural. É perdida a oportunidade de uma possível incorporação genuína dos sentidos dos índios, da forma de mundo que eles carregam. Uma das teorias de Viveiros de Castro exibe o pensamento ameríndio como sendo mais que um "objeto" de estudo, como um "interlocutor", nas palavras dele, um "(co)respondente dialógico que tem o aspecto de uma sofisticada cosmopolítica indígena" (CASTRO, 2012, p. 156).

Para chamá-la "pensamento", porém, é preciso que sejamos capazes de, imitando ao nosso modo os índios (que não é o modo deles), pensar o pensamento como algo que, se passa pela cabeça, não nasce nem fica lá; ao contrário, investe e exprime o corpo da cabeça aos pés, e se exterioriza como afeto incorporante: predação metafísica, canibalismo epistêmico, antropofagia política, pulsão de transformação do e no outro. (CASTRO, 2012, p. 157) 
No entanto, em vez do pensamento ameríndio, uma nova commoditie é produzida a partir da cristalização de sentido de um elemento cultural demasiado complexo.

A poesia, expressão que guarda uma potência da linguagem e, portanto, do pensamento, passa por processo semelhante quando é reduzida à ilustração de um pensamento, equivalência de uma imagem, figuração de um mundo ou exaltação do belo. Não só a poesia, mas toda a literatura que promove importantes reflexões, por vezes, passa por processo semelhante de cristalização de sentido. É fato que o modo de produção da literatura é diferente daquele utilizado pela indústria em que o resultado é um produto, fruto de um trabalho alienado. Entretanto, às vezes, a maneira como o livro assume valor de troca ou como a figura do escritor passa a possuir valor de mercado são suficientes para que o elemento literário assuma status de produto.

Livros que são utilizados em projetos de arquitetura para enfeitar ambientes; escritores que passam por certa celebrização de um grande público que, muitas vezes, não conhece sua obra - vale mencionar as edições de obras de Paulo Leminski e Ana Cristina Cesar em cores chamativas, da editora Companhia das Letras, que, a despeito de serem obras poéticas de difícil leitura e compreensão, representaram grande sucesso de vendas ${ }^{2}$; consumo da literatura de forma redutora para aplacar as próprias carências, mesmo quando essas obras são complexas e tentam desenvolver complexas leituras acerca do mundo no qual o artista se encontra inserido; leituras recortadas de obras que se inserem em contextos específicos de crítica e que, assim, podem chegar a dizer exatamente o oposto daquilo que a totalidade da obra diz; enfim, são várias as formas de promover uma transformação da produção artística em coisa produzida e que pode ser comercializada.

Se pensarmos no índio, na cultura indígena, ou no escritor e na produção artística que o acompanha, é possível traçarmos um paralelo entre eles sob o ponto de vista de que ambos se transformaram em um mercadoria cultural desejada como qualquer outro bem de consumo. A cultura do índio e a literatura passam por um processo de cristalização do seu significado, resultando em uma apreensão redutora que pode, assim, ser comercializada sem oferecer perigos, questionamentos, críticas a quem vende ou compra. O mercado agrega um valor de mercado para parte da imagem do índio e da literatura.

\section{Todos no chão}

A partir do processo ocorrido ao índio, talvez seja uma metáfora interessante olharmos para o mapa de Belo Horizonte, cidade construída para ser a capital de

\footnotetext{
${ }^{2}$ Ainda sobre dois poetas citados acima, durante os lançamentos das respectivas obras, foi possível observar vendedores de livrarias circulando pelas lojas com camisas que reproduziam a capa dos livros, também em cores berrantes, com recortes de versos complexos, reduzindo-os a fórmulas de autoajuda.
} 
Minas Gerais no fim do século XX. No centro da capital, pode-se observar que as ruas recebem nomes de cidades, estados e de tribos indígenas. As avenidas não obedecem padrões bem definidos.

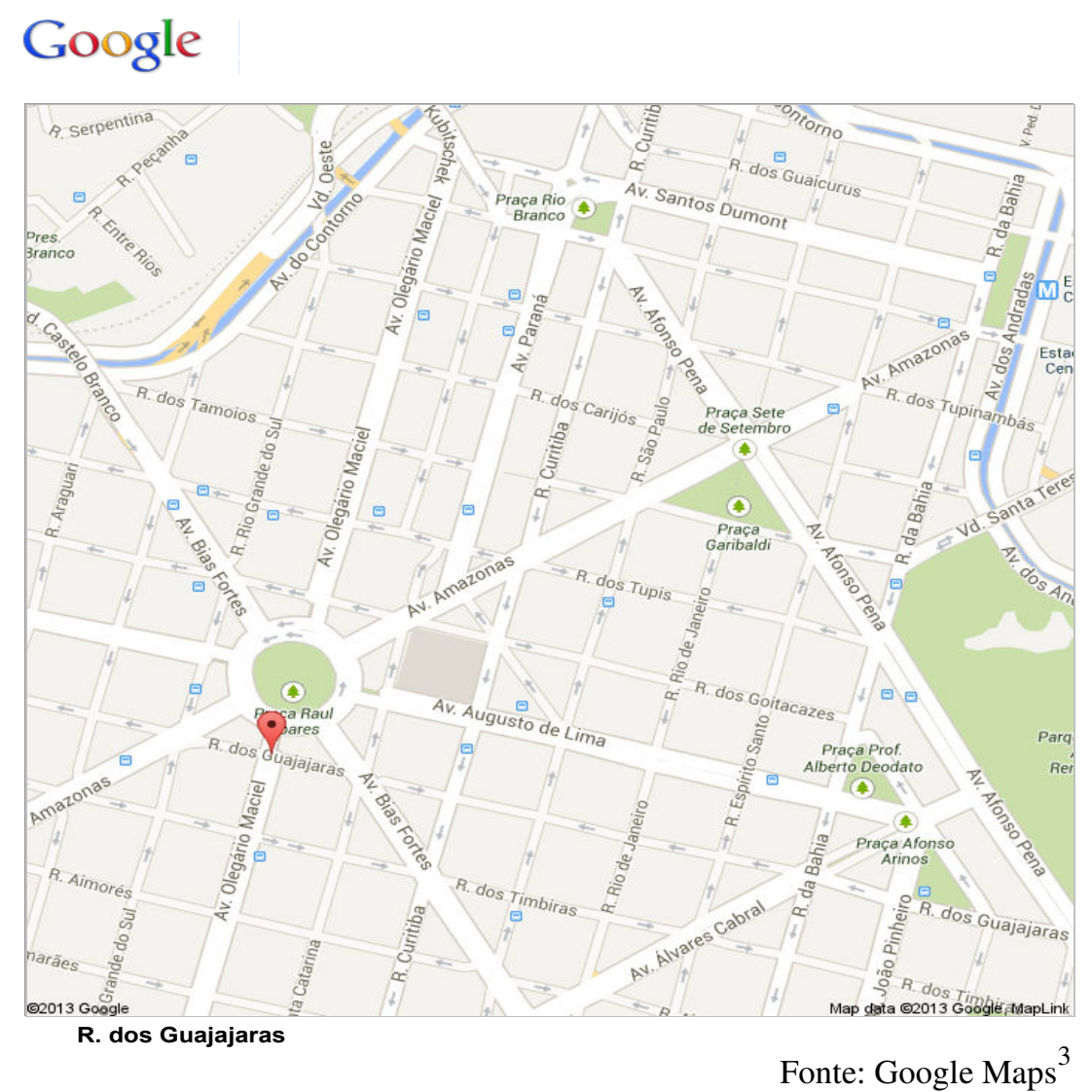

Apesar da morte de milhões de índios a partir da chegada dos portugueses ao continente americano, é curioso pensar na dita homenagem a eles. Os irmãos Lô e Márcio Borges acentuam, em uma canção do Clube da Esquina, o fato dos nomes dos índios terem sido "plantados" no coração da cidade. Sabendo da importância da terra para esses povos, é no mínimo irônico pensar que lhes foi tomado algo muito importante para homenageá-los, colocando nomes das tribos no chão que eles sequer podem mais pisar.

\section{RUAS DA CIDADE \\ Lô Borges e Márcio Borges \\ Guaicurus Caetés Goitacazes \\ Tupinambás Aimorés \\ Todos no chão \\ Guajajaras Tamoios Tapuias}

\footnotetext{
${ }^{3}$ Disponível em: https://maps.google.com.br/maps $/ \mathrm{ms} ? \mathrm{msa}=0 \& \mathrm{msid}=21172881939 \ldots 0.022724 \& \mathrm{t}=\mathrm{m} \& \mathrm{z}=16 \& \mathrm{vpsrc}=6 \& \mathrm{e}$ i=TMMbUqqXAcX1tgem24DIAQ\&pw=2. Acesso em: 08/2013.
} 


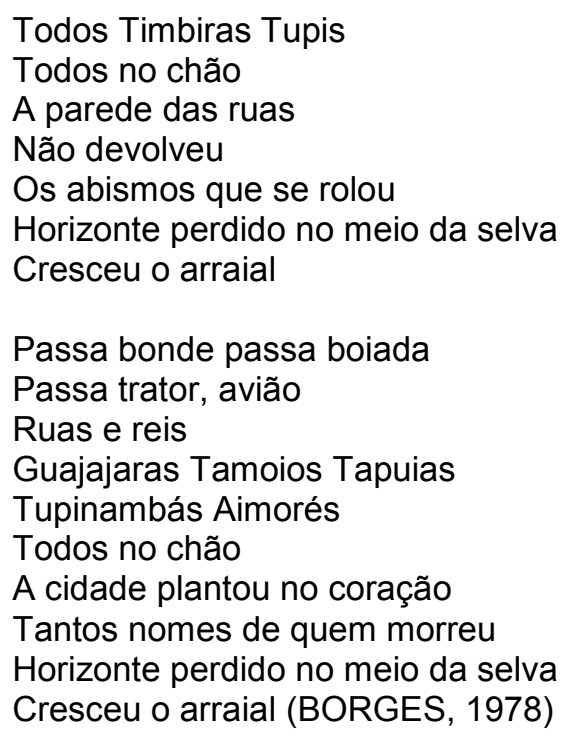

Além disso, vale chamar a atenção para outro elemento fundamental para o raciocínio proposto aqui: a homenagem suscita a imagem dos índios a virar concreto ou de que o concreto agora cobre os índios mortos. Temos a ideia do índio sendo cristalizado, reduzido, rígido como um concreto e, consequentemente, tendo interrompido seu processo de construção de sentido em relação a si mesmo ou diante do outro.

No estado de São Paulo, além de várias cidades com nomes oriundos de palavras indígenas, na capital paulista, muitas ruas também receberam nomes de diversas etnias indígenas. Moema, um bairro de luxo de São Paulo, também possui um sequência de nomes indígenas designando suas ruas.

\section{Google Maps Alameda dos Aicás - Indianópolis}

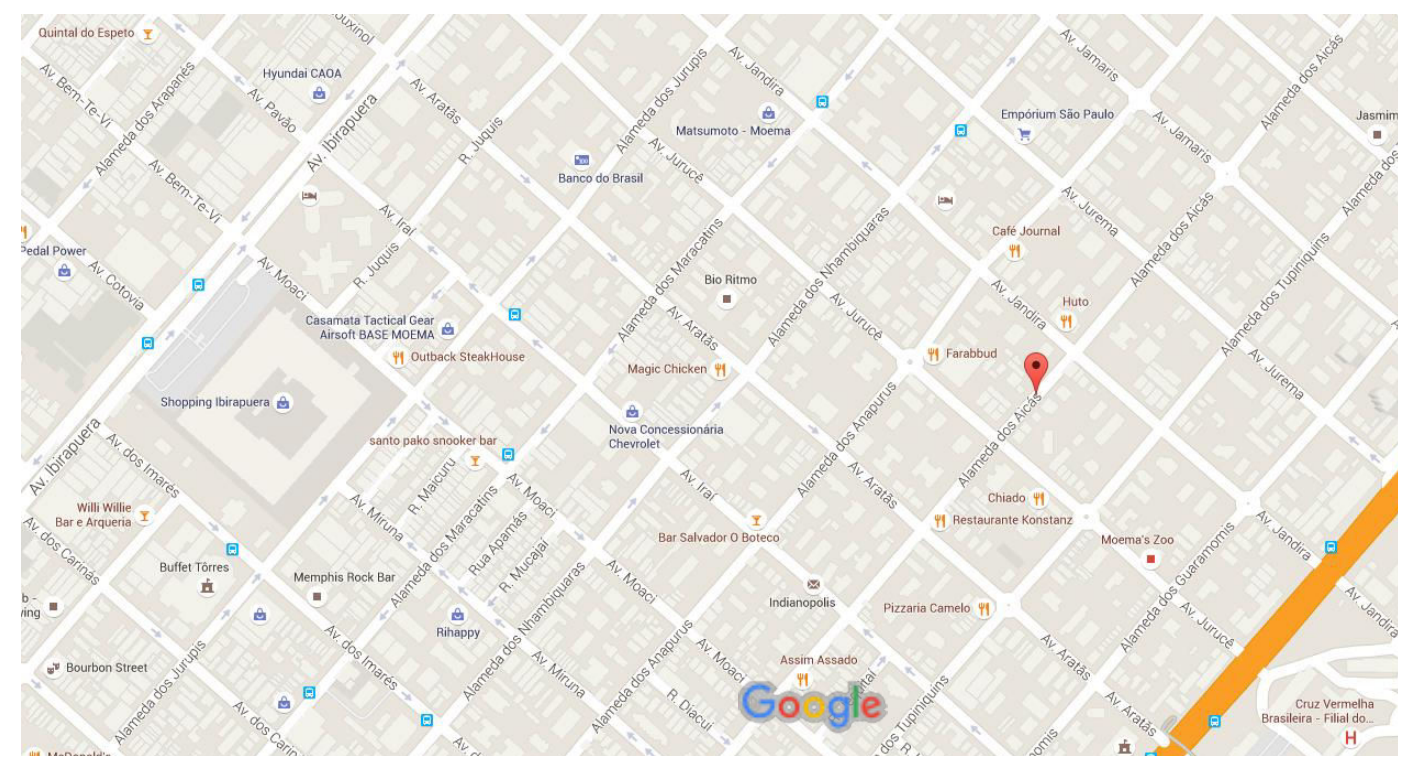


Voltando a Belo Horizonte, podemos observar processo semelhante com os escritores. Em 2009, o então governador Aécio Neves e o prefeito Fernando Pimentel assinaram um decreto que nomeava "Linha Verde" a via expressa para carros que ligaria a capital ao aeroporto. Ainda dentro desse projeto de ligação $\mathrm{BH}-$ Confins, todos os viadutos que passassem por cima da Linha Verde receberiam nomes de escritores.

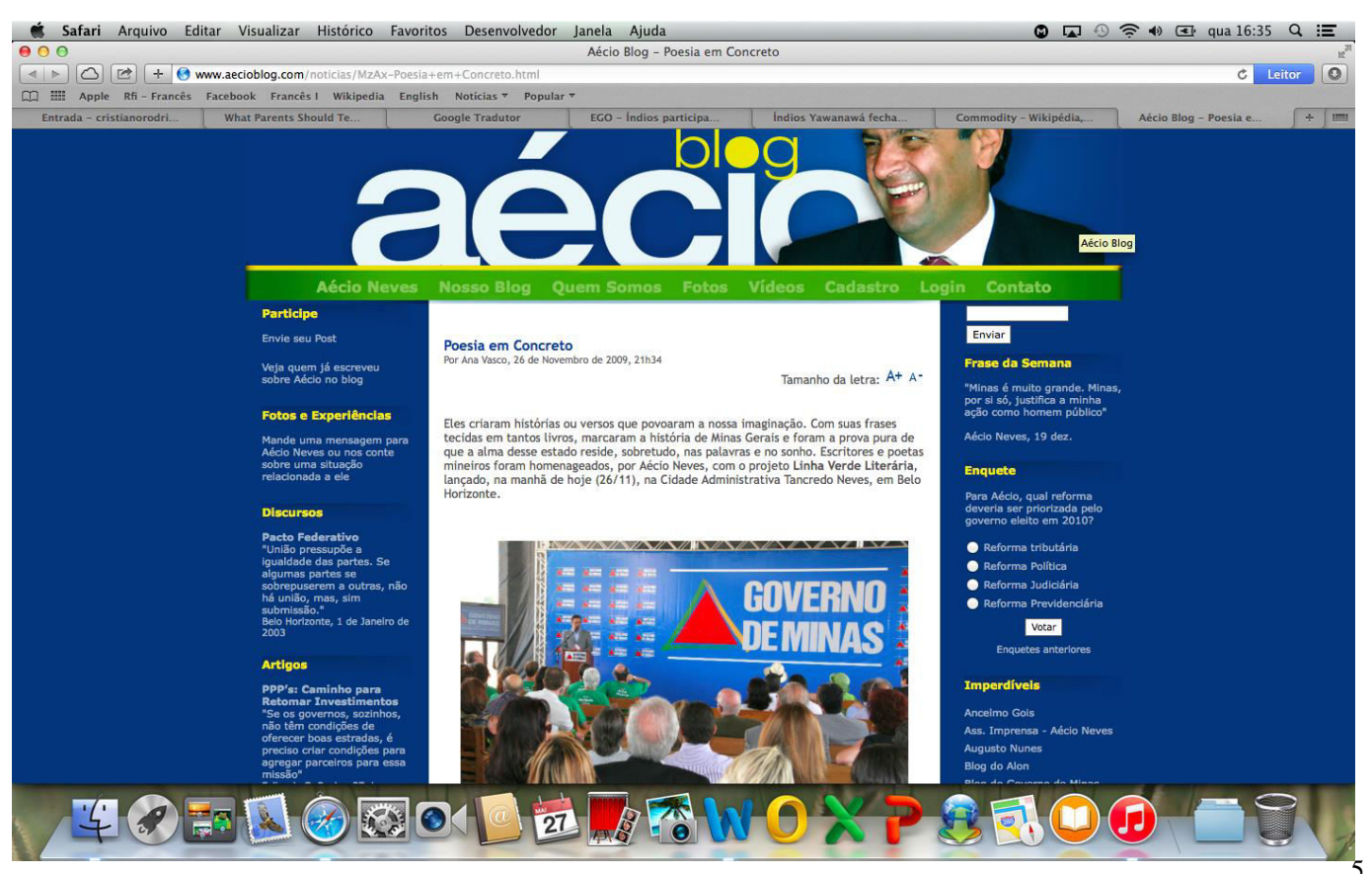

Fonte: Blog Aécio

\footnotetext{
${ }^{4}$ Disponível em: https://goo.gl/maps/NLU1K21rahA2. Acesso em: 04/2016.

5 Disponível em: http://www.aecioblog.com/noticias/MzAx-Poesia+em+Concreto.html. Acesso em: 10/2015.
} 


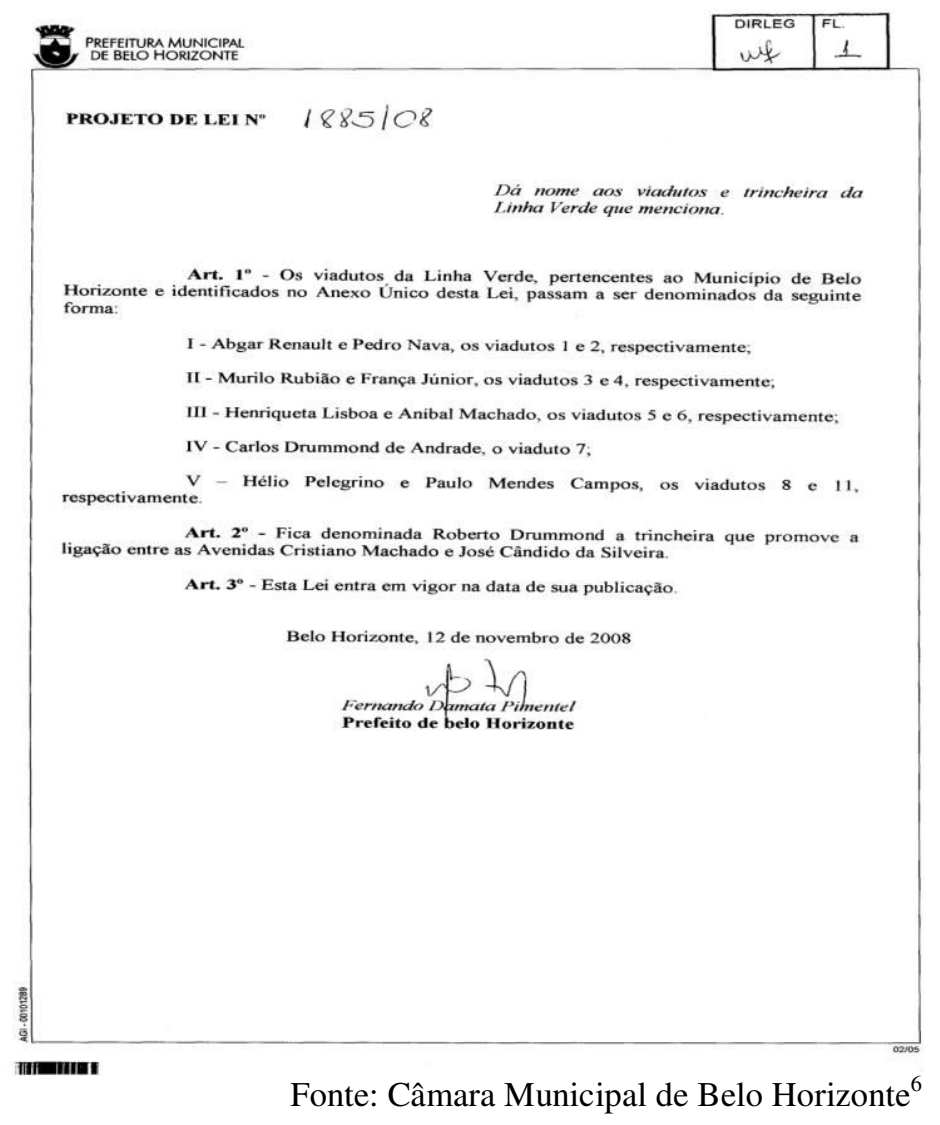

${ }^{6}$ Disponível em: http://www.cmbh.mg.gov.br/images/stories/secren/dezembro08/Projeto\%201885-08Proposicao\%20de\%20Lei\%20801-080001.pdf. Acesso em: 2016. 


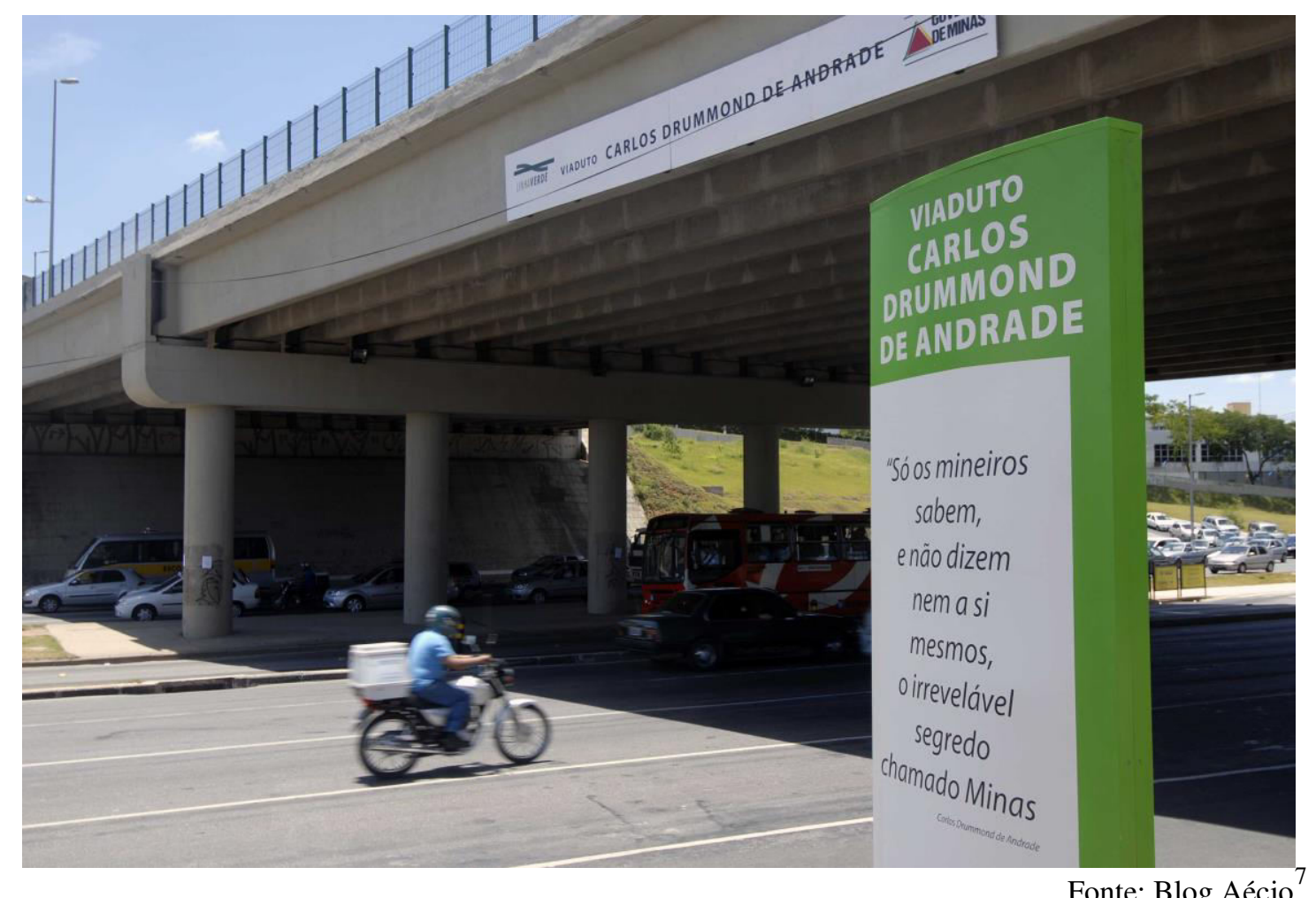

Mais uma vez, é possível observar a imagem da cristalização da significação dos escritores e de suas obras. Pedro Nava, Henriqueta Lisboa, Fernando Sabino e Drummond são alguns dos nomes que, a despeito da construção de sentido que eles promovem e que poderia ser uma possível leitura de mundo - mais humanizada, não excludente, capaz de formular elementos tão complexos da nossa sociedade são supostamente homenageados. A potência do pensamento desses escritores é reduzida a uma reificação simplória. Novamente, temos aqui o peso do concreto que enrijece ideias e pessoas para a sociedade atual e para o mercado também, uma vez que essas obras foram utilizadas como bens adquiridos em campanhas eleitorais de políticos que, muitas vezes, atuam em direção a certa desumanização de grupos de excluídos sociais. As homenagens a escritores são uma forma de escravização do sentido que eles possuem, uma redução, uma forma de engessamento e codificação vazia. É cruel pensar que políticos lançam supostas homenagens à literatura, a escritores, quando na verdade estão atuando em sentido oposto: não houve qualquer movimento significativo para ampliar o incentivo à leitura ou a rede de bibliotecas públicas da cidade de Belo Horizonte.

Antes de terminar, vale ressaltar que apesar da transformação da cultura indígena e da literatura em produtos culturais não se trata de uma mercadoria como outra qualquer, resultado de uma linha de produção. Segundo Mário Fernando Bolognesi, em A mercadoria cultural:

\footnotetext{
7 Disponível em: http://www.aecioblog.com/noticias/MzAx-Poesia+em+Concreto.html. Acesso em: 10/2015.
} 
Os processos artísticos e culturais não se reduzem, imediata e sumariamente, à concepção do trabalho alienado, tal como aplicado na relação capitalista de produção. A superação da alienação está presente na arte (ou também em outras atividades, tais como na ciência e na filosofia), se esta assim o quiser, possibilitando o desenrolar de um lado utópico e crítico, de exploração das faculdades humanas para além das atividades fundantes da produção econômica (BOLOGNESI, 1996, p. 83).

Como vimos no pensamento de Eduardo Viveiros de Castro, a cultura indígena também pode oferecer resistência aos processos ambientais catastróficos em curso atualmente. Ou seja, também os índios, apesar de em alguns momentos chegarem a ser agentes nos domínios do capital, guardam uma postura para além do consumo e representam uma sociedade que é um "protótipo de futuro", um exemplo de resistência para um mundo em ruínas. A mesma postura também pode ser vista em relação à literatura que nunca deixa de ir além das simples relações de consumo e de conseguir formular, por meio da linguagem inteligível, uma série de sentimentos, afetos e reflexões sobre o mundo do homem contemporâneo, bem como sobre as experiências significativas do ser humano de hoje.

"Os herdeiros de todos os que venceram antes" (BENJAMIN, 2004, p. 221) parecem fazer questão de marcar suas conquistas, mesmo que inconscientemente, em parte grande dos elementos que lhe são significativos.
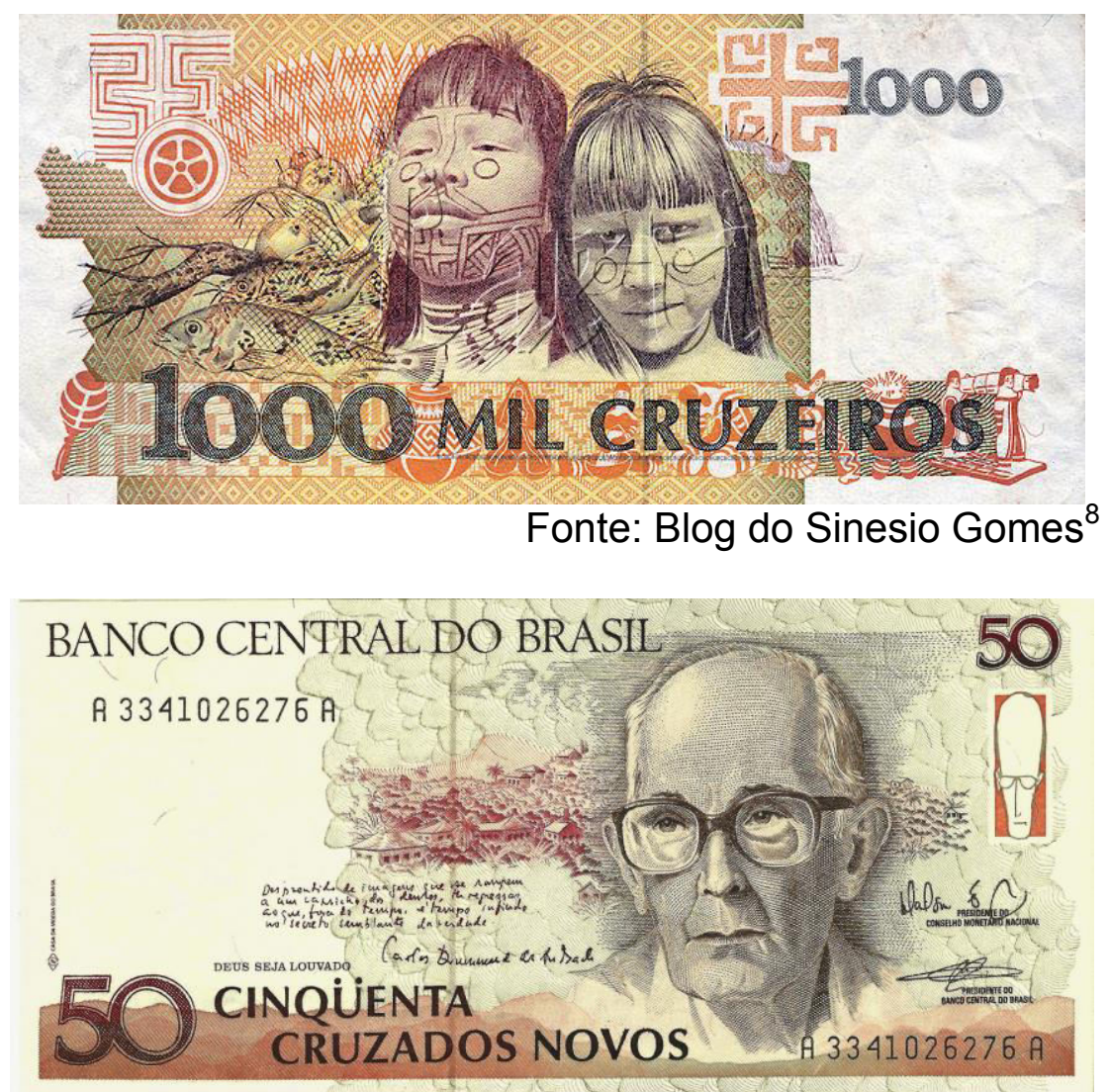

\footnotetext{
${ }^{8}$ Disponível em: http://sinesiorgomes.blogspot.com/2015_03_01_archive.html. Acesso em: 03/2016
} 
Fonte: Blog do Sinésio Gomes ${ }^{9}$

Não se pode negar que as homenagens aos índios e escritores fazem com que eles sejam lembrados, principalmente, se lembrarmos que até nomes que não devem ser lembrados senão para combatê-los como os de generais da Ditadura Militar que nomeavam espaços públicos. No entanto, tais homenagens são a cristalização do sentido, a potência domada para que tais elementos virem commodities, produto ou, às vezes, literalmente, dinheiro. Não se deve esquecer que essa forma de lembrança também é uma comunicação das tribos vencidas, são monumentos da barbárie passada.

Voltando à problematização feita por Machado de Assis, talvez não tenha se realizado aquele matrimônio suscitado por ele. Porém, é indiscutível que a fatalidade da história tenha sido cruel aos poetas, bem como aos índios, mesmo sabendo que não cabe comparar como a crueldade acometeu cada um desses grupos.

\section{Referências}

ASSIS, Machado de. Instinto de nacionalidade. In: Machado de Assis: crítica, notícia da atual literatura brasileira. São Paulo: Agir, 1959, p. 28-34.

BENJAMIN, Walter. Magia e técnica, arte e política. Obras Escolhidas. Volume 1. Trad.: Sérgio Paulo Rouanet. São Paulo: Brasiliense, 2004.

BOLOGNESI, Mário Fernando. A mercadoria cultural. In: Trans/Form/Açao, $\mathrm{n}^{\circ} 19$, São Paulo, 1996, p. 75-86.

BORGES, Lô; BORGES, Márcio. Ruas da cidade. In: NASCIMENTO, Milton et al. Clube da esquina 2: Milton Nascimento. São Paulo: EMI-Odeon, 1978. 1 CD.

CASTRO, Eduardo Viveiros de. A indianidade é um projeto de futuro, não uma memória do passado: entrevista com Eduardo Viveiros de Castro. Prisma Jur., São Paulo, v. 10, n. 2, p. 257-268, jul./dez. 2011.

CASTRO, Eduardo Viveiros de. "Transformação" na antropologia, transformação da "antropologia". In: MANA, N ${ }^{\circ}$ 18(1): 2012, p. 151-171.

NAHOUM, André Vereta. Selling "cultures": the traffic of cultural representations from the Yawanawa. 2013. Tese (Doutorado em Sociologia) - Faculdade de Filosofia, Letras e Ciências Humanas, Universidade de São Paulo, São Paulo, 2013.

Disponível em: <http://www.teses.usp.br/teses/disponiveis/8/8132/tde-15012014102023/>. Acesso em: 14/04/2016.

SZTUTMAN, Renato; NASCIMENTO, Silvana; MARRAS, Stellio. O chocalho do xamã é um acelerador de partículas: entrevista com Eduardo Viveiros de Castro. In: SZTUTMAN, Renato (Org.). Eduardo Viveiros de Castro - Encontros. Rio de Janeiro: Beco do Azougue, 2007.

\footnotetext{
${ }^{9}$ Disponível em: http://sinesiorgomes.blogspot.com/2015_03_01_archive.html. Acesso em: 03/2016
} 
Recebido em 28/03/2016

Aprovado em 30/04/2016

elSSN: $2179-8478$

DOI: $10.17851 / 2179-8478.10 .88-99$ 